\title{
ANALISIS PENDAPATAN KELOMPOK NELAYAN MELALUI PROGRAM BANTUAN KAPAL PENANGKAPAN IKAN DI DESA TOOLAWAWO KECAMATAN LALONGGASUMEETO KABUPATEN KONAWE
}

\author{
Revenue Analysis Of Fisherman Groups Through The Fishing Vessel Assistance \\ Program In Toolawawo Village Lalonggasumeeto District Konawe District
}

\author{
Restu Destriani ${ }^{1}$, Sarini Yusuf ${ }^{2}$ dan Irdam Riani $^{2}$ \\ 1) Mahasiswa Jurusan/Program Studi Agrobisnis Perikanan FPIK UHO \\ 2) Dosen Jurusan/Program Studi Agrobisnis Perikanan FPIK UHO \\ E-mail : restudestriani4@gmail.com
}

\begin{abstract}
ABSTRAK
Penelitian ini bertujuan untuk mengetahui dampak dari program bantuan kapal penangkapan ikan terhadap pendapatan nelayan di DesaToolawawo Kecamatan Lalonggasumeeto Kabupaten Konawe. Salah satu program bantuan fasilitas penangkapan ikan adalah kapal 3 GT yang digunakan untuk mengumpulkan data sejak bulan Januari-Mei 2020, yang diberikan kepada 4 orang nelayan sebagai responden. Teknik penarikan sampel dalam penelitian ini adalah total sampling. Data diperoleh melalui wawancara dengan menggunakan kuesioner dan dianalisis dengan metode kuantitatif menggunakan rumus pendapatan. Hasil penelitian menunjukkan bahwa pendapatan nelayan sebelum menerima bantuan kapal sebesar Rp1.067.750/trip atau Rp3.203.250/bulan dan setelah menerima bantuan pendapatan meningkat sebesar Rp2.611.550/trip atau Rp7.834.650/bulan. Artinya program bantuan kapal 3 GT mampu meningkatkan pendapatan nelayan sebesar $40,9 \%$.
\end{abstract}

Kata Kunci : Nelayan, Program Bantuan Kapal, Pendapatan

\begin{abstract}
This research aims to determine the impact of the fishing vessel assistance program on the income of fishermen in Toolawawo Village, Lalonggasumeeto District, Konawe Regency. One of the fishing facilities assistance programs is the 3 GT vessel, uses for collecting data from January-May 2020, the vessel was given to 4 fisherman asrespondents. The sampling technique in this study was total sampling. Data obtained through interviews using a questionnaire and analyzed by quantitative methods using the income formula. The results showed that the income of fisherman before receiving boat assistance was IDR 1,067,750/trip or IDR 3,203,250/month and after receiving assistance their income increased IDR 2,611,550/trip or IDR 7,834,650/month. This means that the 3 GT boat assistance program was able to increase fisherman's income by $40.9 \%$.
\end{abstract}

Keywords: Fisherman, Boat Assistance Program, Income

\section{PENDAHULUAN}

Salah satu kelompok masyarakat yang memanfaatkan sumber daya perikanan adalah masyarakat nelayan. Masyarakat nelayan merupakan kelompok masyarakat yang melakukan aktifitas usaha dengan mendapat penghasilan bersumber dari kegiatan menangkap ikan. Semakin banyak hasil tangkapan maka semakin besar pula pendapatan yang diterima dan pendapatan tersebut sebagian besar untuk keperluan konsumsi keluarga.

Masyarakat nelayan identik dengan kemiskinan banyak hal yang menyebabkannya yaitu kurangnya modal 
yang dimiliki para nelayan, teknologi yang dimiliki, rendahnya akses pasar dan rendahnya partisipasi masyarakat dalam pengolahan sumber daya alam. Ada penyebab lain yang non ekonomi atau biasa disebut faktor sosial seperti pertumbuhan jumlah penduduk yang tinggi, rendahnya tingkat pendidikan dan rendahnya tingkat kesehatan serta alasan lain seperti sarana dan prasarana umum diwilayah pesisir. Kurangnya perencanaan spasial yang menyababkan tumpang tindihnya beberapa sektor suatu kawasan polusi dan kerusakan lingkungan (Prakoso, 2013).

Adapun program pemberdayaan masyarakat nelayan yang sudah berjalan di Desa Toolawawo Kecamatan Lalonggasumeeto Kabupaten Konawe yaitu sarana dan prasarana penunjang kegiatan penangkapan ikan antara lain kapal dan peralatan penangkapan seperti alat tangkap pancing rawai. Melalui program bantuan sarana penangkapan diharapkan dapat meningkatkan kapasitas usaha nelayan, meningkatkan jumlah kapal perikanan yang berkualitas dan bersertifikat, meningkatkan produktifitas usaha penangkapan ikan, meningkatkan mutu hasil ikan dan meningkatkan pendapatan nelayan. Program bantuan kapal di Desa Toolawawo Kecamatan Lalonggasumeeto diusulkan dan diturunkan kepada koperasi nelayan dan dioperasikan oleh kelompok nelayan. Bantuan yang diterima berupa kapal berukuran 3 GT, dan alat tangkap pancing rawai.

Tujuan dari penelitian ini adalah untuk mengetahui dampak dari program bantuan kapal penangkapan ikan terhadap pendapatan nelayan di Desa Toolawawo Kecamatan Lalonggasumeeto Kabupaten Konawe.

\section{METODE PENELITIAN}

Penelitian ini dilaksanakan pada Bulan Mei 2020 di Desa Toolawawo Kecamatan Lalonggasumeeto Kabupaten Konawe. Metode pengambilan sampel dalam penelitian ini menggunakan total sampling. Jenis data yang digunakan dalam penelitian ini yaitu data primer dan data sekunder. Agar dapat menjawab permasalahan yang diajukan dalam penelitian ini, maka digunakan analisis kualitatif.

\section{a. Penerimaan (TR)}

Menurut Rahardja (2008) rumus untuk mengetahui penerimaan yaitu:

$\mathrm{TR}=\mathrm{Q} \cdot \mathrm{P}$

Dimana :

$\mathrm{TR}=$ Total Revenue $(\mathrm{Rp})$

$\mathrm{Q} \quad=$ Quantity $(\mathrm{Rp})$

$\mathrm{P} \quad=$ Price $(\mathrm{Rp} / \mathrm{kg})$

\section{b. Pendapatan}

Rumus pendapatan adalah sebagai berikut: (La Ola, 2014).

$\pi=\mathrm{TR}-\mathrm{TC}$

Dimana :

$\pi \quad=$ Pendapatan

$\mathrm{TR}=$ Total revenue $(\mathrm{Rp})$

$\mathrm{TC}=$ Total Cost $(\mathrm{Rp})$

\section{HASIL DAN PEMBAHASAN}

\section{Biaya Produksi Nelayan Sebelum dan Sesudah Menerima Bantuan Kapal}

Biaya merupakan salah satu faktor penentu kelancaran dalam menjalankan suatu usaha. Biaya yang dimaksud dalam penelitian ini yaitu semua biaya yang dikeluarkan nelayan dalam melakukan penangkapan ikan. 
Tabel 1. Rata-Rata Biaya Operasional yang Dikeluarkan Nelayan Sebelum dan Setelah Menerima Bantuan Kapal Penangkapan Ikan di Desa Toolawawo Kecamatan Lalonggasumeeto.

\begin{tabular}{|c|c|c|c|}
\hline No & Uraian & Sebelum (Rp/Bulan) & Sesudah (Rp/Bulan) \\
\hline 1 & BBM & 675.000 & 1.425 .000 \\
\hline 2 & Es & 648.000 & 720.000 \\
\hline 3 & Konsumsi & 375.000 & 1.050 .000 \\
\hline 4 & Rokok & 247.500 & 351.000 \\
\hline 5 & Korek & 11.250 & 21.000 \\
\hline & Rata-Rata & 1.956 .750 & 3.567 .000 \\
\hline
\end{tabular}

Sumber : Data Primer Setelah Diolah, 2020

Biaya operasional yang dikeluarkan nelayan sebelum menerima bantuan dengan menggunakan kapal 1 GT dan alat tangkap pancing ulur sebesar Rp1.956.750/bulan, setelah menerima bantuan kapal 3 GT menggunakan alat tangkap pancing ulur dan pancing rawai biaya yang dikeluarkan meningkat sebesar Rp3.567.000/bulan. Biaya operasional yang dikeluarkan oleh nelayan lebih tinggi dalam hal penggunaan BBM karena operasi penangkapan nelayan berpindah-pindah dan tidak memililki fishing ground yang tetap yaitu di perairan Labengki, Perairan Sombori, dan perairan Menui. Hal ini sesuai dengan penelitian Asri $d k k$., (2019) mengemukakan bahwa input penggunaan BBM tidak efisien, operasi penangkapan, nelayan pancing rawai dasar di Kecamatan Rumbia Tengah yang pada umumnya berpindah-pindah dan tidak memiliki fishing ground yang tetap, sehingga menggunakan BBM yang cukup banyak untuk mencari lokasi-lokasi penangkapan yang lainnya.

\section{Penerimaan}

Penerimaan nelayan yang mengoperasikan kapal bantuan untuk menangkap ikan di Desa Toolawawo berbeda-beda tergantung pada jumlah produksi ikan, jenis ikan, dan harga jual ikan. Penerimaan nelayan di Desa Toolawawo Kecamatan Lalonggasumeeto dapat dilihat pada Tabel 2.

Tabel 2. Rata-Rata Penerimaan Nelayan Sebelum dan Sesudah Menerima Bantuan Kapal Penangkapan Ikan di Desa Toolawawo Kecamatan Lalonggasumeeto

\begin{tabular}{llccc}
\hline No & Uraian & Sebelum (Rp/Bulan) & Sesudah (Rp/Bulan) & Persentase (\%) \\
\hline 1 & Nelayan I & 5.145 .000 & 11.949 .300 & 50,9 \\
2 & Nelayan II & 5.175 .000 & 10.854 .000 & 49,1 \\
\hline & Rata-Rata & $\mathbf{5 . 1 6 0 . 0 0 0}$ & $\mathbf{1 1 . 4 0 1 . 6 5 0}$ & \\
\hline
\end{tabular}

Sumber : Data Primer Setelah Diolah, 2020

Rata-rata penerimaan nelayan sebelum menerima bantuan sebesar Rp5.160.000/bulan sedangkan rata-rata penerimaan nelayan sesudah menerima bantuan kapal penangkapan ikan sebesar Rp11.401.650/bulan. Penerimaan nelaya n sebelum dan setelah menerima bantuan meningkat pada nelayan I sebesar 50,9\% dan pada nelayan II meningkat sebesar 49,1\%. Hal ini berbeda dengan penelitian Irwanto (2018) rata-rata nilai produksi penerimaan nelayan penerima bantuan kapal dan alat tangkap pancing sebesar Rp13.831.042/bulan sedangkan rata-rata nilai produksi penerimaan nelayan tanpa bantuan sebesar Rp14.378.750/bulan.

Perbedaan penerimaan nelayan sebelum dan sesudah menerima bantuan 
disebabkan karena sebelum menerima bantuan nelayan hanya menggunakan alat tangkap pancing ulur yang dioperasikan di sekitar laut Lalonggasumeeto dengan hasil tangkapan berupa ikan cakalang, ikan katamba, ikan putih, ikan sunu dan ikan tenggiri. Hal ini sejalan dengan hasil penelitian Misnawati $d k k$., (2018) yang melakukan penelitian di Desa Wawatu Kecamatan Moramo Utara bahwa jenis ikan hasil tangkapan pancing ulur adalah ikan putih, ikan cakalang, ikan katamba, ikan kerapu, dan ikan tuna. Sedangkan setelah menerima bantuan nelayan menggunakan alat tangkap pancing ulur dan pancing rawai yang dioperasikan disekitar laut pulau Labengki, pulau Sombori dan perairan Menui dengan hasil tangkapan nelayan bermacammacam antara ikan kerapu sunu hitam, ikan sunu merah, ikan putih, ikan tenggiri dan lain-lain. Hal ini sejalan dengan hasil penelitian Franjaya $d k k$., (2018) yang melakukan penelitian di Desa Kota Bani Kecamatan Putri Hijau Kabupaten Bengkulu Utara bahwa hasil tangkapan nelayan pancing rawai terdapat 5 jenis yaitu ikan kerapu, ikan kakap merah, ikan pari, ikan hiu putih, dan guguk atau ikan manyung. Sedangkan hasil penelitian Asri $d k k$., (2019) hasil tangkapan pancing rawai yaitu ikan kerapu, ikan kakap merah, dan ikan kakap putih dengan rata-rata penerimaan nelayan pancing rawai yaitu Rp30,06/trip.

\section{Dampak Program Bantuan Kapal Terhadap Pendapatan Nelayan}

Pendapatan nelayan penerima bantuan kapal merupakan panghasilan bersih yang diterima nelayan dari usaha penangkapan ikan yang dijalani, baik ketika sebelum menerima bantuan dan setelah menerima bantuan. Irwanto (2018) mengemukakan bahwa salah satu indikator untuk mengetahui keberhasilan suatu uasaha tani atau usaha perikanan dapat diketahui dengan melakukan perhitungan pendapatan. Besarnya pendapatan nelayan dapat dilihat pada Tabel 3.

Tabel 3. Pendapatan yang Diperoleh Nelayan Sebelum dan Sesudah Menerima Bantuan Kapal Penangkapan Ikan di Desa Toolawawo Kecamatan Lalonggasumeeto.

\begin{tabular}{ccccc}
\hline No & Uraian & Sebelum $(\mathbf{R p} /$ Bulan) & Sesudah $(\mathbf{R p} /$ Bulan) & Persentase (\%) \\
\hline 1 & Nelayan I & 3.433 .500 & 8.541 .300 & 54,2 \\
2 & Nelayan II & 2.973 .000 & 7.128 .000 & 45,8 \\
\hline & Rata-Rata & 3.203 .250 & 7.834 .650 & \\
\hline
\end{tabular}

Sumber : Data Primer Setelah Diolah, 2020

Rata-rata pendapatan nelayan sebelum menerima bantuan dengan menggunakan kapal berukuran 1 GT dengan menggunakan alat tangkap pancing ulur sebesar Rp3.203.250/bulan, sedangkan rata-rata pendapatan nelayan setelah menerima bantuan dengan menggunakan kapal berukuran 3 GT menggunakan alat tangkap pancing ulur dan pancing rawai sebesar Rp7.834.650/bulan. Perbedaan pendapatan nelayan sebelum dan setelah menerima bantuan meningkat pada nelayan I sebesar $54,2 \%$ dan pada nelayan II meningkat sebesar 45,8\%. Hal ini berbeda dengan penelitian Sapriani $d k k$., (2016) bahwa rata-rata pendapatan nelayan setelah menerima program adalah sebesar Rp2.882.917/trip lebih besar dari sebelum menerima program yang hanya sebesar Rp1.277.322/trip, tingkat pendapatan nelayan setelah menerima paket program kegiatan penyediaan rehabilitasi sarana dan prasarana produksi perikanan tangkap mengalami peningkatan yang sangat signifikan ditunjukkan dengan rata-rata peningkatan pendapatan sebesar 136\% dari sebelum menerima paket program 
bantuan. Sedangkan hasil penelitian Arwana $d k k$., (2016) rata-rata pendapatan nelayang yang mendapatkan bantuan perahu mesin tempel $15 \mathrm{PK}$ dengan menggunakan alat tangkap pancing dan jaring sebesar Rp323.486,81/trip atau Rp6.469.736,20/ bulan secara rill lebih besar daripada pendapatan nelayan tanpa mendapatkan bantuan sebesar Rp315.200,93/trip atau Rp6.304.018,60/bulan. Pemberian bantuan alat tangkap mempunyai dampak terhadap peningkatan pendapatan nelayan sebesar $2,6287 \%$.

Perbedaan pendapatan nelayan sebelum dan setelah menerima bantuan kapal penangkapan ikan dipengaruhi oleh janis perahu yang digunakan. Meningkatnya jenis perahu yang digunakan nelayan, akan mempengaruhi daya jelajah nelayan dalam melakukan penangkapan, semakin tinggi daya jelajah ada kemungkinan jumlah tangkapannya juga semakin meningkat. Arwana dkk., (2016) mengemukakan jenis perahu berpengaruh sangat nyata terhadap pendapatan nelayan. Dengan meningkatnya jenis perahu, dari jukung tradisional menjadi jukung dengan menggunakan mesin tempel atau jukung mesin tempel 8 PK ditingkatkan menjadi 15 PK pendapatan nelayan akan meningkat, meningkatnya jenis perahu yang digunakan nelayan, akan mempengaruhi daya jelajah nelayan dalam melakukan penangkapan, semakin tinggi daya jelajah ada kemungkinan jumlah tangkapannya juga semakin meningkat.

Kegiatan pemberdayaan melalui bantuan kapal penangkapan ikan ini merupakan kegiatan yang sangat bermanfaat dan memberikan dampak baik bagi nelayan terutama dalam membantu nelayan meningkatkan hasil tangkapan dan pendapatan keluarga. Pemanfaatan program bantuan kapal yang dipergunakan oleh nelayan dapat membantu masyarakat dalam memanfaatkan potensi perairan laut untuk peningkatan pendapatan nelayan (Asmaida, 2014; Ardianti, 2019; La Suhu, $d k k, 2020)$. Demikian halnya dalam penelitian ini, anggota kelompok yang bergabung dalam koperasi dapat memanfaatkan kapal bantuan terutama nelayan yang belum memiliki sarana penangkapan yang optimal dalam memanfaatkan potensi perikanan tangkap di Desa Toolawawo.

\section{SIMPULAN}

Berdasarkan hasil dan pembahasan, maka dapat disimpulkan bahwa dengan adanya bantuan kapal ini memiliki dampak positif terhadap peningkatan pendapatan nelayan sebelum dan sesudah menerima bantuan kapal penangkapan ikan di Desa Toolawawo Kecamatan Lalonggasumeeto.

\section{UCAPAN TERIMAKASIH}

Ungkapan terimakasih, Penulis curahkan kepada kedua orang tua tercinta Ayahanda Aswan dan Ibunda Andi Hasmawati yang senantiasa bersabar dalam mendidik dan mengasuh, mendoakan, memotivasi Penulis serta kepada teman-teman Agrobisnis Perikanan khususnya angkatan 2016 yang memberikan motivasi, serta telah banyak membantu Penulis selama menjalani studi.

\section{DAFTAR PUSTAKA}

Ardianti, N. Rafidah, Khairiyani, 2019. Program Pemberdayaan Ekonomi Masyarakat Pesisir melalui Pemberian Kapal dan Alat Tangkap di Desa Kuala Simbur (Doctoral Disertation Jambi Universitas Islam Negeri Sulthan 
Thaha Saifuddin Jambi).

Arnawa, I. K., Purnama I. B., dan Gede, M. K. A. 2016. Dampak Bantuan Sarana Perikanan Tangkap Terhadap Peningkatan Pendapatan Nelayan Di Kabupaten Gianyar Provinsi Bali. Fakultas Pertanian Universitas Mahasaraswati Denpasar. Jurnal Manajemen Agribisnis. Vol. 4 (1).

Asmaida, 2014. Evaluasi Program Pemberdayaan Ekonomi Masyarakat Pesisir melalui Pemberian Kapal Ikan beserta Alat Tangkap di Kabupaten Tanjung Jabung Timur. Jurnal Ilmiah Universitas Batanghari Jambi Vol. 14 (4).

Asri, M., Budiyanto., \& Irdam, R. 2019. Analisis Usaha Penangkapan Ikan Dengan Alat Tangkap Pancing Tonda Dan Pancing Rawai Dasar Di Kecamatan Rumbia Tengah Kabupaten Bombana. Jurnal Sosial Ekonomi Perikanan FPIK UHO. Vol. 4 (2) : 1-9.

Franjaya, W. L., Zamdial, A. M., \& Muqsit, A. (2018). Analisis Produktivitas Dan Teknis Penangkapan Rawai Dasar Di Desa Kota Bani Kecamatan Putri Hijau Kabupaten Bengkulu Utara. Jurnal Enggano. Vol. 3 (2), 261274.

Irwanto. 2018. Analisis Pendapatan Nelayan Penerima Bantuan Pemerintah Daerah di Kecamatan Ampenan Kota Mataram. Artikel Ilmiah. Fakultas Pertanian. Universitas Mataram.

La Ola, L. O. 2014. Efisiensi Biaya Produksi dan Daya Saing Komoditi Perikanan Laut di Pasar Lokal dan Pasar Ekspor. Jurnal
Bisnis Perikanan. Vol. 1 (1). FPIK UHO Kendari.

La Suhu, B., Pora, R., Kurniawan, M. 2020. Program Pemberdayaan Ekonomi Masyarakat Nelayan di Wilayah Pesisir Kota Tidore Kepulauan (Studi di Desa Maitara Kecamatan Tidore Utara). Jurnal Govermentof Archipelago-JGOA. Vol. 1 (1), 17-24.

Misnawati., Budiyanto., Piliana, W. O. 2018. Metode Penangkapan Ikan dan Pendapatan Nelayan di Desa Wawatu Keamatan Moramo Utara Kabupaten Konawe Selatan Provinsi Sulawesi Tenggara. Jurnal Sosial Ekonomi Perikanan. Vol 3 (4) : 229-253.

Prakoso, J. 2013. Peranan Tenaga Kerja, Modal, dan Teknologi Terhadap Peningkatan Pendapatan Nelayan di Desa Asemdoyong Kecamatan Taman Kabupaten Pemalang. Skripsi S1. Universitas Negeri Semarang.

Rahardja, P. 2006. Teori Ekonomi Mikro Suatu Pengantar, Edisi Ketiga, Jakarta: Lembaga Penerbit Fakultas Ekonomi Universitas Indonesia.

Saprani, S., Mahyudin, I., \&Agusliani, E. 2016. Kajian Program Kegiatan Penyediaan dan Rehabilitasi Sarana dan Prasarana Produksi Perikanan Tangkap terhadap Peningkatan Pendapatan Nelayan di Kabupaten Tanah Laut Kalimantan Selatan. Enviro Scient eae. 12 (2), 104-112. 